\title{
Imagining in response to fiction: unpacking the infrastructure
}

\author{
[penultimate version; forthcoming in Philosophical Explorations]
}

\author{
Alon Chasid* \\ Department of Philosophy, Bar-Ilan University, Ramat-Gan, Israel
}

\begin{abstract}
Works of fiction are alleged to differ from works of nonfiction in instructing their audience to imagine their content. Indeed, works of fiction have been defined in terms of this feature: they are works that mandate us to imagine their content. This paper examines this definition of works of fiction, focusing on the nature of the activity that ensues in response to reading or watching fiction. Investigating how imaginings function in other contexts, I show, first, that they presuppose a cognitive infrastructure encompassing at least one additional kind of mental state, whose role is to determine, to some degree, truth in an imaginary world. I then discuss the implications for the definition of fiction, showing that the definition should be refined to accommodate the structure that imagining presupposes: a work counts as fiction just in case it mandates us, not only to imagine, but to engage in a more complex mental activity, an activity that in addition to imagining, involves positing a backdrop for our imaginings.
\end{abstract}

Keywords: works of fiction; fictional worlds; imagination; belief-like imagining; imaginary truths; Kendall Walton.

\footnotetext{
*Email: alon.chasid@gmail.com
} 


\section{Introduction}

Works of fiction are alleged to differ from works of nonfiction in instructing their audience to imagine their content. Indeed, works of fiction have been defined in terms of this feature: they are works that mandate us to imagine their content. ${ }^{1}$ Philosophers tend to accept this definition, acknowledging its deficiencies and often modifying it to rectify them. In this paper, I examine this definition, focusing on the mental activity that ensues in response to fiction. Showing that imagining presupposes a complex mental infrastructure, I argue that the definition of fiction in terms of imagining requires modification to take this mental infrastructure into account.

My focus will be Kendall Walton's (1990) version of the 'mandate to imagine' definition of fiction, since the revision I propose is based on lacunae in Walton's definition. After presenting Walton's definition and the problems it raises, I put forward an account of the mental activity we engage in when we imagine. Examining how imaginings function in contexts not related to fiction, I show that imaginings presuppose a cognitive infrastructure comprising the positing of an imaginary world, as well as awareness that the imagined content is putatively assessed for truth in that world. I then discuss the implications of this account of imagining for the definition of fiction. I argue that the definition should be modified to accommodate the infrastructure that imagining presupposes: a work counts as fiction just in case it mandates us not only to imagine, but also to posit a 'backdrop' for our imaginings. Lastly, I show how the modified definition resolves additional problems, pointed out in the literature, that beset the 'mandated-imagining' definition of fiction.

\section{Fiction and imagining}

On a widely-held view of fiction, works of fiction direct us to imagine their content, whereas works of nonfiction do not direct us to imagine their content. Works of nonfiction are often 
taken to suggest that their content be believed, or mentally represented by a cognitive state other than imagining.

Defining fiction as that which mandates that its content be imagined is appealing for several reasons. For one thing, when appropriately construed, the content of a work of fiction is not really believed. Even if we sometimes speculate as to whether the content is true and therefore should be believed, our mode of engaging with fiction is not ordinarily swayed by such speculation: knowing that we are reading, watching (listening to, etc.) fiction, we are aware that the work's content need not be considered true or believed.

Moreover, as Walton (1990) shows, our response to fiction seems to be the same kind of response we have when engaging in pretense, games of make-believe, daydreaming, etc. Since imagining is the kind of response we have in the latter contexts, it follows that we respond to works of fiction, too, by imagining.

Let me further elucidate the last point. Following Walton (1990), it is widely accepted that when we pretend, play games of make-believe, daydream, etc., we engage in imagining. The term 'imagining' can denote several different kinds of mental states, but in the aforementioned contexts, the mental state we are in has a specific profile: it is a representational state that is belief-like in certain functional respects. ${ }^{2}$ Setting aside the differences between various accounts of imagining, there is broad agreement that imaginings are related to other kinds of mental states in a manner similar to that in which beliefs are related to those kinds of states or to similar ones. Imaginings often generate emotional responses, conative states, motivations to act in certain ways, and so on, much as beliefs do. For instance, a child pretending that a neighbor is a dragon may, when she sees the neighbor, imagine that a dragon is nearby, and thus may have a fear-like emotion, or be in a desire-like state, 'wishing' the dragon would go away. 
This kind of imagining also characterizes engagement with works of fiction. Watching a horror movie in which a green monster is approaching, we are in a fear-like state that is somehow directed toward that monster (Walton 1990, 196ff); imagining the events recounted in Anna Karenina, we are moved by the fate of its heroine (Radford 1975); watching an episode of "The Sopranos," we may be in a desire-like state, 'wanting' Tony Soprano to elude the police (Egan and Doggett 2012). The fact that our mental responses to works of fiction are functionally similar to our imaginings when daydreaming, pretending, etc., shows that belief-like imagining is indeed the cognitive response to fiction.

Nevertheless, defining fiction as that which directs us to imagine raises several problems. As will be discussed in section 6, examples have been devised for the purpose of arguing that works of nonfiction can mandate imagining, and works of fiction can mandate believing. Rather than beginning by tackling these alleged counterexamples, I will address them after discussing Walton's definition and the specific problems it raises (section 3), since these problems hint at a revision of the prevailing definition of fiction that may resolve both problems raised by Walton's definition (section 5), and certain problems raised by the counterexamples (section 6).

\section{Walton's definition of fiction}

Walton first defines the notion of "fictionality" or "fictional truths" (1990, subsection 1.5; see also Friend 2008, 154ff). He argues that a proposition is fictional (i.e., fictionally true; true in a game's or a work's world) if and only if it is "to be imagined" $(1990,39)$. Walton then defines works of fiction as "works whose function is to serve as props in games of makebelieve" (72), where props are "generators of fictional truths" (37). A work counts as fiction just in case its "function" 3 is to mandate that we imagine certain propositions, propositions that, by virtue of this mandate, become true in the work's world, that is, become fictional 
truths. Works of nonfiction are distinguished from works of fiction in that they are "used to claim truth for certain propositions rather than to make propositions fictional [i.e., true in the work's world, AC]. Instead of establishing fictional worlds, they purport to describe the real world" (70).

Walton's definition of a work of fiction is strict: the propositions a work of fiction mandates us to imagine must be the propositions that are true in the work's world ("fictional truths"). On his view, the characteristic feature of a work of fiction-the 'generating' of fictional truths, thereby 'establishing' a fictional world - means that the fictional work necessarily mandates us to imagine all, and only, the propositions that are true in its world. The idea is that since the general notion of fiction assumes that a proposition is fictionally true if and only if there is "a prescription or mandate" that it be imagined $(1990,39)$, when this prescription is issued by a work of fiction, in particular, it follows that the proposition is true in the work's world.

Walton (2015, ch. 2) admits that his definition is flawed. He discusses several types of cases which demonstrate the untenability of identifying the propositions that a work of fiction invites us to imagine with the propositions that are considered true in the work's world. One type of case adduced by Walton includes a direct prescription to imagine "fictional falsehoods." A murder mystery, e.g., "may trick readers into thinking that the butler is the villain... [whereas] the UPS deliveryman, not the butler, committed the crime" $(2015,24)$. Another type of case features what Walton calls "meta-representations" (20): pictures that depict other pictures, stories that encompass other stories, fictions that involve illusions, etc. These works may direct the audience to imagine propositions that, though true in the 'secondary' representation (i.e., the depicted picture, or the story or illusion within the main story), are false in the work's world. 
Yet another sort of case is based on Walton's thesis that "all imagining involves a kind of self-imagining (imagining de se)" (1990, 29; cf. 2015, 31). That is, we necessarily imagine ourselves as being part of the fictional world, whereas it is usually false that we exist in the work's world. This sort of purported paradox is readily apparent in visual fictions. When we watch a play or movie, or look at a picture that depicts, say, an unseen murder, it is true in the work's world that no one (other than the perpetrator) sees the murder, yet due to the nature of the medium - theater, video, images — we are required, according to Walton, to imagine seeing the murder $(2015,28 \mathrm{ff})$.

Walton concludes that his initial definition is inadequate: a work of fiction can mandate that we imagine not only fictional truths, but also fictional falsehoods. Walton maintains that "fictional truths come in clusters" $(2015,18)$ : the world of the game of make-believe, which includes the imaginer, differs from the world of the play or of the movie (the work's world); the world of the story differs from that of the story-within-the-story; and so on. In general, the propositions we are mandated to imagine - the "to-be-imagined" propositions, as Walton puts it - are related to a specific 'cluster,' in which they are considered true. Yet Walton concedes that his definition of fiction as that which mandates that we imagine the propositions that are true in the work's world (Walton 1990) does not tell us how differences between clusters are generated:

I don't know how to fill the gap; I don't know what, in addition to a prescription to imagine, is required to make a proposition fictional in the world of a given work. ...We somehow 'construct' a fictional world, recognizing a subset of the to-be-imagined propositions as constituting it. We deploy a more substantial notion of fictionality than I previously thought, one that is not in any obvious way reducible to or explainable in terms of imaginings. $(2015,28)$ 
The gap, however, is not unbridgeable. Indeed, Walton's claim that a work may prescribe the imagining of fictional falsehoods points to an important infrastructural aspect of the overall mental activity we engage in when we imagine, whether or not our imagining is a response to a work of fiction. The problems noted by Walton regarding his definition of fiction can be resolved if the definition is modified so that it takes this infrastructural aspect of imagining into consideration.

Let us consider the overall mental activity we engage in when we imagine, which I will call 'an imaginative project,' in cases that do not involve works of fiction. The definition of fiction can then be revisited, and the problems identified by Walton can be addressed (section 5), as can other problems ensuing from the definition (section 6).

\section{Belief-like imaginings}

\subsection{Imaginary falsehoods}

Belief-like imaginings are commonly claimed to be like beliefs in certain functional respects (see section 2 and note 2). Other similarities between imaginings and beliefs ensue from their representational character. For instance, much as we can believe either true or false propositions, so we can imagine either true or false propositions; imagining a proposition, like believing it, does not entail that the proposition is true. This similarity is somewhat trivial, but points to a related similarity between beliefs and imaginings that is quite significant for understanding fiction. As Walton's examples demonstrate, we often imagine propositions that are false in the fictional world; e.g., in response to an implicit directive in the aforementioned murder mystery, we imagine the fictional falsehood that the butler, not the UPS driver, is the villain. 
It thus seems that imagining a proposition does not entail even that the proposition is true in the fictional or imaginary world. This 'representational' analogy between beliefs and imaginings means that much as the content of beliefs can be either true or false simpliciter, the content of imaginings can be either true or false in the fictional, or imaginary, world. Indeed, the content of imaginings is assessed for truth in the pertinent imaginary world much as the content of beliefs is assessed for truth simpliciter.

I will now show that imaginings in general-i.e., not just cases involving works of fiction - do not entail that their content is true in the imaginary world. Before doing so, two clarifications are in order. First, it is important to distinguish between, on the one hand, the terms 'fictional world,' 'fictional truth,' 'fictional falsehood,' and on the other hand, the terms 'imaginary world,' 'imaginary truth,' 'imaginary falsehood.' The former refer to worlds, truths, or falsehoods that are assumed by a work of fiction, whereas 'imaginary world' ('imaginary truth,' etc.) refer to the world, truths, etc. that the imaginer posits in an 'imaginative project'-i.e., the overall mental activity she engages in when she imagines. Imaginative projects arise not only in response to reading or watching fiction, but also in other contexts, e.g., daydreams, games of make-believe, etc. The world of a daydream is an imaginary world; it is not a fictional world, because daydreaming doesn't usually ensue in response to fiction. (Henceforth I will refer to imaginary worlds, imaginary truths, and imaginary falsehoods as 'i-worlds,' 'i-truths,' and 'i-falsehoods,' respectively).

The difference between fictional worlds and i-worlds raises the question of whether the iworld that we normally posit in response to engaging with a work of fiction is identical to the work's fictional world (i.e., the propositions assumed by the work to be true); this will be discussed in section 5. A related question is how a fictional world is revealed to us, that is, how the propositions that a work implicitly or explicitly assumes to be true - those that, as Walton initially put it, are to be imagined—are divulged. This question is addressed at length 
in Walton (1990, ch. 4; see also Currie 1990, ch. 2 and Davies 2007, ch. 4). Walton adduces "principles of generation," namely, ways of interpreting a work and revealing the propositions it takes to be true. In this paper, I will not address the question of how we come to know a work's fictional truths. Regardless of how a work discloses the propositions it assumes to be true, fictional truths are, I contend, conceptually different from i-truths: i-truths are posited by the imaginer in any imaginative project, whether or not it arises in response to a work of fiction.

Another point to keep in mind is that although my account is not committed to any specific theory about the metaphysics of 'fictional' or 'imaginary' worlds, for convenience, I will use, as a baseline, Walton's characterization of fictional worlds as "sets of propositionsas-indicated-by-a-given-work" (1990, 66-67). Indeed, fictional worlds may be constituted by the same set of propositions, yet differ because they are set down by different works. Similarly, I will identify an imaginary world with the set of propositions assumed by the imaginer in a specific imaginative project. As in the case of fictional worlds, i-worlds may be constituted by the same set of propositions, yet differ because they are posited in different imaginative projects — projects involving different, and differently-related, mental states (imaginings, emotional responses, conative states, imagery, etc.).

Consider the following example:

Fred's Daydream: Relaxing on the couch, Fred finds himself imagining that he is rich: he owns many properties, and socializes with other wealthy businesspeople. He proceeds to imagine discovering that, to his great dismay, he isn't rich at all: the properties actually belong to his uncle, who misled Fred into thinking that they were his so that he would shoulder the burden of maintaining them. In fact—so he imagines—he owns no property but a house inherited from his parents. 
Fred is impecunious and does not have an uncle: the content of his imaginings is utterly false. Yet on a plausible interpretation of Fred's daydream, some of the propositions he imagines are true in the daydream's i-world, and some are false in that world: the propositions that he owns no property aside from the inherited house, and that he has an untrustworthy uncle, are true in his daydream's i-world, whereas the propositions that he is rich, that he owns many properties, that his uncle is trustworthy, are false in that i-world. Fred's imaginings do not entail that their content is true in the pertinent i-world. In this respect, his imaginings are similar to beliefs: much as beliefs do not render their content true simpliciter, imaginings do not render their content true in the pertinent i-world.

It follows that, to render the imagined content $\mathrm{i}$-true, Fred must engage in a separate mental act, which I'll call 'positing.' That is, in addition to imagining the said propositions, Fred also 'establishes' an i-world by positing, probably spontaneously and without much awareness, that certain propositions are i-true. Fred indeed imagines the said propositions to be i-true (as he, similarly, believes various propositions to be true), yet imagining a proposition to be i-true does not make it i-true (just as believing a proposition to be true does not make it true). In general, from the perspective of imagining, the imaginer is aware that the imagined propositions are putatively assessed for truth in an i-world (much as, in believing, a believer is aware that the believed propositions are assessed for truth simpliciter. $)^{4}$

Against this idea, it might be argued that imagining a proposition does render the imagined proposition true in the pertinent world. Fred thus imagines only i-truths: at the start of his daydream he imagines the i-truths that he is rich, that he owns many properties, etc., and later he imagines the i-truths that he isn't rich, he owns only the house he inherited, and so on. This entails that Fred's imaginings pertain to two different i-worlds, one in which he is rich, etc., and another in which he isn't. A difficulty with this suggestion is that if Fred 
imagines only i-truths, the said emotional and cognitive responses to the shift in his imaginings do not arise. Imagining the i-truth that he is rich, and then imagining the i-truth that he isn't rich (a proposition that is true in a different i-world), will not generate horror-, surprise-, or discovery-like feelings. For what could be, say, 'surprising,' when one shifts from imagining a proposition to imagining its negation, if the 'contrary' imaginings pertain to different worlds? To address this problem, those who object to my proposal might argue that the surprise- and discovery-like feelings pertain only to the second stage of Fred's daydream. That is, Fred initially imagined the i-truth that he was rich, and then shifted to imagining a different i-truth - i.e., a proposition that is true in a different $\mathrm{i}$-world - that it is discovered that he isn't rich. The discovery- and surprise-like feelings are thus related only to Fred's second-stage imaginings, which are directed at a different i-world. This proviso sustains the objector's claim that all Fred's imaginings have i-true content.

I do not deny that imaginings can, by conjuring different i-worlds, have solely i-true content. My claim is that this is not necessarily the case. For in imagining a proposition, nothing prevents us from proceeding, while directing our imagining at the same i-world, to imagine its negation. Described in greater detail, Fred's daydream may illustrate this feature of imagining. First, when Fred proceeds to imagine that he is not rich, in addition to having discovery- and surprise-like feelings, Fred also has a sense that his initial imaginings were incorrect - an incorrectness analogous to the incorrectness we ascribe to the real-world beliefs we set aside upon adopting contrary views. Yet if, as per the objection, Fred's initial imaginings were directed, not at the i-world in which he discovers his impecunity, but at a different i-world, and reflected the truth in that world (namely, that he is rich), he would not ascribe a sense of incorrectness to them.

Second, suppose Fred imagines that he is a wealthy businessperson attending a cocktail party at which someone shows him documents proving that he isn't rich at all; i.e., Fred 
imagines the conjunction that he's rich and that he's reading documents proving that he isn't rich. On this description of Fred's daydream, the proposition that Fred is rich is assessed for truth in the same i-world in which the proposition that he is reading documents proving that he isn't rich is assessed for truth. For Fred imagines reading the documents $a$ a rich businessperson. Indeed, only after imagining that conjunction does Fred imagine that he isn't rich, react with dismay- and surprise-like feelings, and ascribe a sense of incorrectness to the imagining that he was rich.

Examples of such spontaneous imaginative projects abound. You might imagine that you've lost your wedding ring, and that, dejectedly rummaging for your phone to call and tell your spouse, you feel a small metal object: you haven't lost your ring, it's there in your bag! Since the proposition that you've lost your ring is assessed for truth in the same world in which the proposition that, as you rummage through your bag to find your phone, you discover that the ring is there, is assessed for truth, you ascribe 'incorrectness' to your imagining that your ring was lost, you have a relief-like feeling, etc.

In short, Fred's imaginings, and other spontaneous imaginings, may incorporate not only i-true, but also i-false content. Recall that, when we engage in an imaginative project the parameters of which are stipulated by a work of fiction, we usually direct our imaginings at a single world. ${ }^{5}$ When one imagines, e.g., in Walton's murder-mystery example, that the butler is the murderer, one's imagining is directed at the same world at which one's subsequent imagining that the butler is not the murderer is directed.

Yet there seems to be a crucial difference between spontaneous imaginative projects and projects that are mandated by a work of fiction. Whereas a work of fiction includes an 'external,' imaginer-independent standard (namely, what the work assumes to be true) against which the imagined content is putatively assessed for truth, there is no such standard for spontaneous imaginings. If Fred's daydream incorporates no such external standard, how can 
Fred be described as first imagining an i-falsehood, and then an i-truth? The answer is that itruths need not be determined by an external, imaginer-independent standard. As I explain in subsection 4.2, the mental act of positing i-truths can be spontaneous: much as the state of belief-like imagining can arise spontaneously, so too an i-world can be established spontaneously.

Of course, i-worlds may be relatively indeterminate. It is, e.g., plausible that Fred posits the i-truth that he isn't rich only at the second stage of his daydream, whereas at the beginning of the daydream, the i-world is indeterminate in this respect. Moreover, specific itruths may not be posited at all, in which case the i-world remains partly indeterminate. This is also true of $\mathrm{i}$-worlds assumed by works of fiction, or posited deliberatively: a murder mystery, e.g., may not specify the murderer's identity (see also the 'that thing with the cup' example in Gendler 2000, 71ff). The crucial point is that even in such cases, one's imaginings are directed at a single i-world, and the imaginer is aware that their content is either i-true or i-false. That is, even without positing specific i-truths, in shifting from imagining one proposition to imagining its negation, an imaginer can direct her imaginings at a single iworld, have surprise- and discovery-like feelings, and ascribe a sense of 'incorrectness' to her initial imagining, much as a believer does in shifting between beliefs.

A different objection to my claim that Fred imagines i-falsehoods might argue that Fred starts his daydream by imagining, not that he is rich, but (the i-truth) that he believes that he is rich. He then imagines that, while believing that he is rich, he reads documents proving that he isn't rich. Though all of Fred's imaginings are directed at the same i-world, Fred imagines no i-falsehoods, since the imagined proposition that Fred believes that he is rich is true in the pertinent $\mathrm{i}$-world. This objection is not trying to make us discuss a different daydream, a daydream about Fred's (false) beliefs. Rather, it claims that, in general, any imagining of 
what seems to be an i-falsehood should be interpreted as an imagining of an i-truth, namely, the $\mathrm{i}$-truth that the $\mathrm{i}$-falsehood in question is believed.

This objection is problematic, since it is implausible to interpret every imagining that seems to have an i-false proposition as its content (e.g., that Fred is rich)—as in fact having the (i-true) content that one believes the i-false proposition (e.g., that Fred believes that he is rich). Consider, again, imaginings that arise in response to works of fiction. We almost never imagine ourselves believing what a work mandates to be 'fictional falsehoods' (e.g., in Walton's murder-mystery example, that the butler is the villain): we simply imagine those falsehoods themselves. Since there is no reason to distinguish, in this respect, between imaginings in response to fiction and spontaneous imaginings, there is also no reason to argue that what seems to be the imagining of $\mathrm{i}$-falsehoods is in fact the imagining of $\mathrm{i}$-truths about false beliefs.

We can therefore stipulate that Fred's daydream starts with Fred's imagining that he is rich. It might, perhaps, be claimed that, since Fred imagines himself to be part of the i-world (i.e., to be an 'i-world character'), it follows that, in addition to imagining that he is rich, he imagines that he believes that he is rich. For my argument, however, the crucial point is that we can ascribe to Fred the imagining that he is rich. Fred proceeds to imagine that, attending the party as a rich businessperson, he is presented with documents showing that he is not rich. On this scenario, the proposition that Fred is rich is i-false. Since Fred has, up to this point, imagined that he is rich (and not, or not only, that he believes that he is rich), he has imagined an i-falsehood.

Consider also cases where the imaginer does not imagine herself to be part of the iworld, and a fortiori does not imagine believing anything. Suppose you imagine a world in which there are no minds, and specifically, no beliefs. Imagining that no beliefs exist, you may imagine, in addition, that there's a gold nugget in a river, and that clouds drift in front of 
the sun, revealing that the object is actually a pebble that was illuminated by the sun. Your imagining that there's a gold nugget in the river, has i-false content; it cannot be interpreted as the imagining that you believe that there's a gold nugget in the river, since you imagined that no beliefs exist.

In sum, Fred's daydream, and other imaginative projects, can incorporate belief-like imaginings with i-false content. Though we often take what we imagine to be true in the pertinent world, we may also intend to imagine, or find ourselves imagining, i-falsehoods.

\subsection{The infrastructure of imaginings}

Since belief-like imaginings can have i-false content (just as beliefs can have false content), it follows that belief-like imaginings in themselves do not render their content i-true. For if they did, imagined propositions would ipso facto (i.e., by virtue of being the content of belief-like imaginings) be i-true (see Chasid, forthcoming, section 2). I am not denying that, in imagining, we often posit that what we imagine is i-true. My point is that even if most, or all, of the propositions we imagine are i-true, it isn't by way of belief-like imagining that they are posited to be i-true. (As mentioned above, the term 'imagining' is used to denote various mental states, and 'imagining a world' could denote, not belief-like imagining, but 'establishing' an i-world, i.e., positing that certain propositions are i-true. It must therefore be kept in mind that in this paper, 'imagining' is used only in the sense of belief-like imagining). ${ }^{6}$

Overall, the idea is that when we imagine, we are aware that what we are imagining is putatively assessed for truth in a world. You may imagine, e.g., that you are sitting in the sun, holding an ice-cream cone, trying the vanilla first, then the chocolate. You may realize that whatever you are imagining is i-true either because you intended to imagine something i-true, or because you implicitly posited that the imagined propositions would be i-true. 
Nevertheless, your belief-like imaginings include a perspective from which facts about the pertinent world are gradually revealed to you: you imagine the taste and texture of the vanilla, then the chocolate, and you respond in a manner similar to that in which you would respond to beliefs about similar real-world events.

But how, if not by belief-like imagining, is an i-world posited? There are various ways to 'establish' an i-world, that is, to posit i-truths. We sometimes posit i-truths by following external instructions or rules stipulating that certain i-truths obtain (e.g., in reading or watching fiction, playing games of make-believe, etc.); we can deliberately set out to posit certain i-truths (e.g., we can intend to imagine that which is i-true); and we can posit i-truths gradually, spontaneously, and without much awareness or deliberate intent, as happens in daydreaming.

Why must we accept that, despite the absence of an 'external,' imaginer-independent standard that determines specific i-truths, spontaneous imaginative projects involve the mental act of positing specific i-truths? Why not say that the i-worlds of spontaneous projects are 'fully' indeterminate? The answer is that most, if not all, spontaneous projects cannot be accounted for without assuming that their i-worlds encompass specific i-truths. For one thing, reflecting on a spontaneous project, we often realize that certain propositions we imagined were i-true. Even if we don't have infallible or privileged access to our mental states, there is no reason to think that we cannot ordinarily (correctly) tell whether what we imagined was true in the pertinent world. It is, e.g., plausible that Fred grasps, upon reflection, that it was true in his daydream's world that he wasn't rich, that his uncle deceived him, etc., and recounts this to his therapist. Had Fred not posited these i-truths, but left the i-world indeterminate, he would probably have reported that he didn't know which of the imagined propositions were i-true. Given that Fred's daydream was spontaneous, he did not (consciously) follow any external directives about what would be considered i-true. 
Nevertheless, his recounting of the daydream demonstrates that he did posit various i-truths, though without immediate awareness of his act of positing.

For another, spontaneous imaginative projects, like intentional projects, are partly determined by facts and beliefs about the real world. When Fred imagines that he is rich, he probably posits that his i-world self, and other i-world objects, have many of their real-world properties (see Chasid 2017). Since the extent to which i-worlds resemble the real world (or what the real world is believed to be like) varies considerably from one project to another, it must reflect the imaginer's posits. In the case of spontaneous projects, these posits are spontaneous. Suppose you spontaneously imagine that you're lunching with Hillary Clinton, the current US President. Though unambiguous, the proposition you imagine, which is false simpliciter, can be part of different imaginative projects. In one project, you implicitly posit that it is i-true that Hillary Clinton won the last election, and imagine that you are having lunch with her. In another project, you posit the i-truth that you're lunching with the realworld US President, but since you mistakenly believe that Hillary Clinton won the election, you imagine the i-falsehood that you're having lunch with her. The difference between these projects cannot be accounted for without invoking your implicit, spontaneous positing of itruths.

Such acts of spontaneously positing i-truths are routine, demonstrating how i-truths can be posited without the guidance of 'external' instructions or standards. A different question is why we spontaneously posit certain propositions to be i-true; similarly, it might be asked why we spontaneously imagine certain propositions. These questions merit separate discussion. For the present argument, the crucial point is that spontaneous projects involve imagining and positing, both of which occur without the imaginer's consciously following external instructions. 
Another crucial point is that, generally, even if an imaginer is aware of the posited itruths, she may nonetheless imagine a proposition she knows to be i-false. In reading the murder mystery a second time, we already know that, in the work's fictional world, and hence in the i-world that we posit in response to reading the mystery, the UPS deliveryman is the murderer. Yet when we read the chapter in which the work implicitly directs us to imagine the i-falsehood that butler is the villain, we ignore our knowledge, and imagine an ifalsehood. Likewise, a novelist can describe scenarios from the perspective of someone who has been fooled into believing that the scenarios are real, though they aren't. In such cases, we posit certain propositions to be i-true (namely, those that obtain in the work's fictional world), but at the same time, being mandated to adopt the duped individual's false perspective, we imagine something we know to be i-false throughout our engagement with the work.

Imagining that which we know to be i-false can also occur spontaneously. Although it is plausible that Fred posits the i-truth that he isn't rich only at the second stage of his daydream, he can also be described as positing that i-truth at the first stage, namely, when imagining its negation (i.e., that he's rich). For instance, intrigued by a movie he recently saw about someone whose uncle misled him into believing that he was rich, Fred finds himself imagining the movie's plot from the first-person perspective, despite positing (at the outset of his project, as per the movie's fictional truth) the i-truth that he is not rich. In short, we often ignore our knowledge about the i-world, and imagine propositions we know to be i-false.

A full analysis of the relations between positing an i-world and imagining either i-truths or i-falsehoods cannot be provided here (for further analysis, see Chasid 2017; forthcoming). For the purpose of my argument, it suffices to recognize the proposed infrastructure of imaginative projects. To recap, drawing on Walton's examples, in which works of fiction mandate us to imagine fictional falsehoods, I have argued that the mental activity we engage 
in when we imagine generally involves both imagining and positing an i-world in which the content of our imaginings is putatively assessed for truth.

\section{Engaging with fiction}

Given the proposed infrastructure of imaginative projects, if a work of fiction mandates us to engage in belief-like imagining, as per the initial definition of fiction, it must also mandate us to posit a world in which the content of our imaginings is assessed for truth. The definition should therefore be modified to accommodate this structure, as follows: a work counts as fiction just in case it mandates us to engage in an imaginative project with respect to its content, a project that involves, in addition to imagining, the positing of an i-world, and awareness that the imagined propositions are putatively assessed for truth in that $\mathrm{i}$-world. The mental infrastructure that imagining presupposes, especially in the case of fictional works, is indeed complex. As Walton's examples demonstrate, engaging with a work of fiction sometimes requires us to distinguish between propositions the work directs us to consider itrue, and propositions it directs us to imagine. Even when we know what the work takes to be true in its world, and we posit those truths in the imaginative project that arises in response to the work, we take the propositions we imagine to be subject to assessment for truth in an iworld.

Having defined works of fiction as works that mandate us to imagine that which is true in their worlds, Walton acknowledged a problem: works of fiction often direct us to imagine that which is false in their worlds, as the examples he adduced demonstrate. My analysis confirms that Walton's concern is warranted, and his definition inadequate. The mental activity that is mandated by a work of fiction is not limited to imagining that which is true in the work's world, and indeed, is not limited to imagining. The fact that belief-like imaginings can have either i-true or i-false content entails that they never arise alone, but are 
accompanied by awareness that their content is assessed for truth in a world, namely, a set of i-truths that the imaginer implicitly or explicitly posits. A work of fiction is meant to guide us in positing its i-world, imagining its content, and being aware that this content is assessed for truth in the posited world.

This modified definition enables us to explain away the difficulties that bedevil Walton's original definition. First, consider cases where a work mandates that we imagine an illusion or false perspective. In such cases, a work mandates us to imagine a proposition (e.g., the butler is the villain) while also mandating us to posit that an incompatible proposition (the deliveryman is the villain) is true in the pertinent world, rendering the imagined proposition ifalse. Indeed, even when we know the i-truth (e.g., in rereading a mystery), imagining ifalsehoods is part of the mandated response to the work.

The proposed analysis also elucidates Walton's idea that fictional truths, as well as imaginings, sometimes “come in clusters" $(2015,18 \mathrm{ff})$. This can now be unpacked as meaning that, in a given imaginative project, several different $i$-worlds are posited. In such cases, we take each cluster of our imaginings to be directed at a different world, in the sense of being putatively assessed for truth in that world. What Walton calls "meta-representations" (a story within a story; a picture within a picture) are mandates to posit different i-worlds. In such cases, we are not directed, as we are in cases of mandated illusions or false perspectives, to imagine i-false propositions, but rather, we are directed to posit a different i-world, and to imagine propositions that are true in that $i$-world.

A third problem ensues from Walton's thesis that all imagining is imagining de se (1990, 29ff); that is, every imagining features the imaginer herself. In particular, when engaging with visual fictions (movies, plays, pictures, etc.), we imagine ourselves seeing the events depicted by the work (1990, ch. $8 ; 2015$, ch. 2 , section 4$)$. This thesis seems at odds with the fact that we are not ordinarily part of the work's world. Moreover, a work may explicitly state 
that the unfolding events are unseen. A visual work of fiction may, e.g., depict a certain murder as not seen by anyone (apart from the perpetrator). In short, if all imagining is de se, and, specifically, every instance of imagining seeing presupposes the imaginer's visual perspective, engaging in imaginative projects entails that we imagine an overt contradiction: we are, and yet are not, part of the i-world. ${ }^{7}$

Walton (e.g.,1990, 62ff) interprets this allegedly paradoxical scenario as an instance of multiple clusters of imaginings. A work's world (which the imaginer isn't part of) and the world of a game of make-believe (the "game world," which the imaginer and the fictional events described by the work are part of), belong to two different clusters. Walton (2015, 33ff) argues that the imaginer may shift, in responding to a single work, between different game worlds or clusters. Thus a work can direct us to imagine, in one cluster, that an event is unthought-of/unseen, and — so Walton argues — in a different cluster, that the event is thought-of/seen.

Walton's explanation may be apt for visual fictions: we may, e.g., imagine seeing a murder, and then imagine (but not imagine seeing), in a different cluster, that the murder is unseen. The problem, however, arises not just vis-à-vis imagining seeing, but vis-à-vis every imagining, given Walton's thesis that all imagining is de se. Whatever cluster an imagining belongs to, this imagining, in this cluster, is also, according to Walton, about us: it entails that we are part of the pertinent world. Since we're part of every imagining, to imagine that we are not part of an imagined event amounts to imagining a contradiction. This problem arises not only vis-à-vis engaging with fiction, but also vis-à-vis spontaneous imaginings. If we find ourselves imagining, say, a tree that no one is aware of (the famous Berkeleian scenario), the content of that imagining must be, according to Walton's 'de se' thesis, contradictory, whatever cluster it belongs to. For in imagining that no one is aware of the tree, we ipso facto imagine ourselves to be somehow or other aware of the tree, since all imagining is de se. 
One way to avoid the apparent paradox is to deny that all imagining is $d e$ se: in imagining an unthought-of tree, e.g., we don't imagine ourselves as part of the scenario. Some philosophers indeed reject the idea that all imagining is de se, and specifically, deny that, in responding to visual fiction, we imagine ourselves seeing the unfolding events (Currie 1990; see also Stock 2013, section 3). Others, however, bring arguments in support of Walton's claim that a subjective perspective is inherent in imagining (Martin 2002; Peacocke 1985). Although the account I am proposing is neutral regarding this debate, it offers an appealing solution to the paradox for those who contend that the imaginer is part of the iworld. Let us accept, then, that when we imagine, we necessarily have a perspective in the $i$ world vis-à-vis the imagined events. On my proposed account, this does not entail that we must imagine ourselves as having that perspective: rather than imagining, we may only posit it to be true in the project's world that we're part of that world, while imagining that we are not part of it; in such a case, we would be imagining an i-falsehood, not a contradiction.

The idea is that even if it is necessary, for various theoretical reasons, to posit a mental state (i.e., a perceptual experience, belief, or other sort of 'awareness') in the i-world, this mental state need not be represented by belief-like imaginings. In other words, those who hold that imaginings entail an i-world mental state of believing, perceiving, etc., as per the 'all imagining is de se' thesis, can argue that this mental state is indeed posited to exist in the project's world, though it isn't imagined. Moreover, given that it is possible to imagine ifalsehoods, the imaginer can imagine that there is no such mental state.

The alleged paradox is thus resolved without applying the 'different clusters' solution to the said examples: it is not necessarily the case that one imagines seeing the unfolding events, and imagines, in a different cluster, that the events are unseen. A more plausible explanation is that one posits that one sees the unfolding i-world events, while imagining, in the same cluster or project, that no one sees them. This account has an important implication regarding 
the distinction between a fictional world (the propositions a work assumes to be true) and an i-world (propositions an imaginer posits to be true in an imaginative project). The i-world we

posit in response to a work is, to a great extent, identical to the work's fictional world. Yet if an i-world necessarily includes the imaginer (as per Walton's ' $d e$ se' thesis), it differs from a work's fictional world in that the imaginer isn't ordinarily part of the latter. Despite this difference, we can imagine the 'work's-world' truth that we are not part of the recounted events. On the 'all imagining is de se' thesis, our belief-like imaginings can freely represent facts of the work's fictional world, even if this world is deemed to differ, for theoretical reasons, from the $\mathrm{i}$-world that we posit in response to the work.

\section{Other concerns}

As mentioned in section 2, the 'mandated imaginings' definition of fiction also raises other problems. The most commonly-raised such concerns involve cases that allegedly show that mandated imagining is unnecessary or insufficient for a work to count as fiction. I will now show how the modified definition addresses some of these concerns. Although my proposed account doesn't purport to solve every problem arising from the initial definition, it distinguishes between the response mandated by works of fiction and other mental activities (e.g., supposing, hypothesizing, assessing counterfactuals, etc.) that are sometimes called 'imagining.'

One argument against the initial definition is that it is too broad, encompassing works of nonfiction as well. Friend (2012), for example, argues that "vividly told non-fiction narratives invite us to imagine what it was like for people to live in different times and places, to undergo wonderful or horrible experiences, and so on" (183). Likewise, works of history that are clearly considered non-fiction may, in making arguments about why events unfolded as they did, ask us to imagine counterfactual scenarios. To make the argument that had Hitler 
been assassinated, his generals would have negotiated peace, for instance, we might be asked to imagine that the 1944 attempt on Hitler's life succeeded (Friend 2011, 171). In the same vein, “Tacitus's Annals and Histories are replete with vivid battles and strikingly eloquent speeches, the contents of which readers are not supposed to believe," as it is clear that Tacitus invented that content (Friend 2008, 160). Since in such cases we are asked to imagine the content of works of nonfiction, mandating that recounted content be imagined is not unique to fiction.

The modified definition addresses this concern by explaining how the response mandated by works of fiction differs from merely entertaining propositions in thought, hypothesizing, assessing counterfactuals, etc. The latter states are not belief-like imaginings: they do not require the positing of a specific $\mathrm{i}$-world, nor do they require any awareness, from the perspective of the imaginer, that the imagined content is assessed for truth in an i-world. We can entertain conjectures, and think about what would happen under certain circumstances, without imagining anything. In such cases, we evaluate the likelihood of various propositions under the specified circumstances, invoking various modes of inference, without necessarily engaging in belief-like imagining. Granted, we can also contemplate counterfactual scenarios by way of engaging in an imaginative project, or imagine, in a belief-like way, a conjectured proposition. But entertaining a proposition in thought, or assessing its likelihood under different conditions, doesn't necessarily involve imagining. Thus when historical works direct us to consider what would have happened had certain events unfolded differently, or to speculate about what went on in the minds of various historical figures, we are not being asked to engage in belief-like imagining. In such cases, we may, perhaps, gain understanding by engaging in belief-like imagining, but nonfiction's primary mandate isn't to stimulate imaginings. By contrast, the primary mandate of works of fiction is indeed to induce the positing of a certain i-world (an i-world largely identical to the world assumed by the work), 
and imagine — in the belief-like sense — various propositions, taking them to be putatively assessed for truth in that i-world.

My account of the role of imagining in fiction does not address the difference between a work's 'primary' and 'non-primary' instructions to the reader, nor does it take a stance on whether a work's mandate is specified by its function or by the author's intention (see note 3). However a work's primary mandate is identified, the proposed account refines our understanding of what it is that works of fiction ask us to do, thereby distinguishing them from works that instruct readers to entertain propositions in thought, assess the truth of counterfactuals, or take on other cognitive states that differ from belief-like imagining; such works are, indeed, deemed nonfiction. Even if a work occasionally directs readers to imagine certain propositions, asking them to 'imagine this and that' (see, e.g., Friend 2012, 183), this instruction does not in itself make that work a work of fiction, since the work's primary mandate may not be to induce us to engage in belief-like imagining.

What about nonfictional works such as Tacitus's Annals and Histories, which describe in detail invented scenes we're not supposed to believe? Again, it doesn't follow that the works mandate us to represent these invented details in belief-like imaginings. What happens in such cases is that, as Friend herself admits, "the reader is supposed to believe that something like this was said, or that something like that happened" $(2008,160)$. That is, we are invited to believe the work's content on some indeterminate level. Most importantly, in such contexts we 'direct' our mind at the real world, and not at an i-world, despite knowing that some of the content is invented. This happens in everyday conversation too: though we are invited to believe our friends' anecdotes, and we ask them to believe ours, we take into consideration the likelihood that the recounted events were not precisely as described. We certainly aren't expected to imagine the narrated details. In such cases we believe the indeterminate content, taking the real world to be something like the described scenarios, and we represent the more 
determinate details by means of thought, not imagination. In the specific case of Tacitus, the determinate content, which his works don't ask us to believe, doesn't count as fiction, since the works don't ask us to represent that content in belief-like imaginings. Although we may imagine that content, we may also simply ponder it, and gain indeterminate knowledge about the described events.

Another criticism of the 'mandated imagining' definition of fiction is that it is too strict, since works of fiction sometimes direct us to believe their content. A novel may have passages in which the author asks us to take her assertions to be true, for instance, if she cites factual background material, or emphasizes lessons she seeks to impart through fictional scenarios (Friend 2012, 184; cf. Stock 2011, 148ff). Some critics of the 'mandated imagining' model of fiction find it problematic that works of fiction often incorporate true propositions, presumably because they contend that fiction must be made-up, and hence cannot be truthful. They therefore add various constraints to ensure that belief is withheld from true propositions that appear in works of fiction. Currie $(1990,45)$, for instance, maintains that if a proposition in a work of fiction is true, it must be true only "accidently" (see too Stock 2013, 2016; cf. Davies 2007, 45ff; Matravers 2014, 22ff).

On the modified definition, however, content the reader is asked to believe isn't problematic, since the prescribed content and beliefs are part of the overall mental activity we engage in when imagining. As emphasized in the literature (Walton 1990, 13, ch. 4; Stock 2011; Nichols 2004; Gendler 2003), imaginings in general may have content that incorporates propositions that are believed, or true simpliciter, not least because some background and conceptual knowledge is essential for constructing the imagined content (see subsection 4.2 above).

Moreover, the proposed account makes possible a more radical scenario. Imagination theorists often contend that although some true content can be imagined, not all of an 
imaginative project's imagined content can be true or identical to one's beliefs: there must be a difference, they claim, between that which is made up and that which is true or believed (see, e.g., Stock 2011; cf. Davies 2007, 45ff). I dispute this claim. For one thing, there is no pre-theoretical reason for insisting that we cannot represent in imaginings that which is represented in our beliefs. Given that some imagined content may, or even must, be identical to the content of one's beliefs, why not say that every imagined proposition can be a proposition that one believes? Indeed, imaginers do not seem preoccupied with denying that they believe the propositions they imagine.

For another, suppose you experience events that merit being narrated in the form of a novel, and you write such a novel. To argue that unless you change some of the content that you believe to be true, you — or anyone familiar with your story—will be unable to read the work as a work of fiction is utterly implausible. Given that you are free (though not obligated) to tell the story precisely as it happened, we can conclude that, in general, we are free to imagine propositions we believe to be true.

On the proposed account, we can imagine the very propositions that we believe to be true, because in imagining, we take the imagined propositions to be assessed for truth in a world posited by the imaginative project in question. The 'invented' aspect of imaginative projects is associated, not only with what we imagine, but with the fact that we posit a world at which our imaginings are directed. ${ }^{8}$ In positing such a world, we need not assume any specific difference between it and the real world: it is sufficient that we direct our belief-like states at a world that, being posited, is not real. An i-world is thus functionally different from the real world: posited in an imaginative project, it is a set of propositions against which the content of imaginings is assessed for truth. Were our mental states, in imagining, directed at the real world, they would be committed to truth simpliciter, responsive to evidence, 
consistent with our beliefs about the real world, and so on, and hence would not be considered imaginings.

Lastly, a work of fiction may direct us, explicitly or tacitly, to adopt certain beliefs, as, for example, when it asks us to embrace a given insight or draw some inference. The iworld's functional distinctness from the real world does not preclude our learning from the imaginative project in question. However, we can learn from works of fiction, and indeed, from any imaginative project, only derivatively. The derivative nature of learning from imagining merits a separate discussion. ${ }^{9}$ The important point is that even if a work of fiction asks us to believe certain propositions, it does not forfeit its status as a work of fiction. For despite the author's directive, the said propositions should be indirectly derived, in a sense that requires further explanation, from the overall mental activity that constitutes the imaginative project mandated by that work of fiction.

\section{Conclusion}

I have argued that characterizing fiction as that which we are directed to imagine is insufficiently specific, since the mental activity associated with imagining comprises not only belief-like mental states, but also awareness that the content of those states is putatively assessed for truth in a world. When we read or watch a work of fiction, we don't merely consider, or entertain in thought, the story it recounts. Rather, we engage in an imaginative project, imagining certain propositions, but also positing, on the basis of what the author tells us, 'facts' of an imaginary world.

In reading or watching a work of fiction, we seek to take the perspective of believers visà-vis the work's world. A defining feature of fiction is thus the relation between a posited iworld and mandated imaginings, a relation that is, I have argued, similar to the relation 
between the real world and our beliefs about it. It is in virtue of this relation that we respond to the work, emotionally, conatively, and cognitively.

\section{Disclosure statement}

No potential conflict of interest was reported by the author.

\section{Funding}

This research was supported by the Israel Science Foundation (grant No. 939/16).

\section{Notes on contributor}

Alon Chasid is a senior lecturer at Bar-Ilan University. He works on the cognitive structure of belief-like imaginings, the cognitive penetration of perceptual experience, pictorial experience, and the relations between perception and imagination.

\section{References}

Chasid, A. 2017. "Imaginative Content, Design-Assumptions and Immersion." Review of Philosophy and Psychology 8 (2): 259-272.

Chasid, A. Forthcoming. "Belief-Like Imagining and Correctness." American Philosophical Quarterly.

Currie, G. 1990. The Nature of Fiction, New York: Cambridge University Press.

Currie, G. 1991. "Visual Fictions.” Philosophical Quarterly 41: 129-143.

Currie, G. and Ravenscroft, I. 2002. Recreative Minds: Imagination in Philosophy and Psychology. Oxford: Oxford University Press.

Davies, D. 2007. Aesthetics and Literature. London: Continuum. 
Doggett, T. and Egan, A. 2007. “Wanting Things You Don't Want.” Philosophers' Imprint 7 (9): 1-17.

Doggett, T. and Egan, A. 2012. "How We Feel About Terrible, Non-existent Mafiosi." Philosophy and Phenomenological Research 84 (2): 277-306.

Friend, S. 2008. "Imagining Fact and Fiction.” In New Waves in Aesthetics, edited by K. Stock and K. Thomsen-Jones, 150-169. London: Palgrave Macmillan.

Friend, S. 2011. "Fictive Utterance and Imagining." Proceedings of the Aristotelian Society, Supp. Vol. 85 (1): 163-80.

Friend, S. 2012. "Fiction as a Genre.” Proceedings of the Aristotelian Society 112: 179-209. García-Carpintero, M. 2019. Normative Fiction-Making and the World of the Fiction. Journal of Aesthetics and Art Criticism 77 (3): 267-279.

García-Carpintero, M. Forthcoming. "Do the Imaginings that Fictions Invite have a Direction of Fit." In The Language of Fiction, edited by E. Maier and A. Stokke. Oxford: Oxford University Press.

Gendler, T. 2000. “The Puzzle of Imaginative Resistance.” Journal of Philosophy 97(2): 5581.

Gendler, T. 2003. "On the Relation between Pretense and Belief.” In Imagination, Philosophy, and the Arts, edited by Matthew Kieran and Dominic Lopes, 125-141. London: Routledge.

Ichino, A. 2019. “Imagination and Belief in Action." Philosophia: 1-18.

Kind, A. 2001. "Putting the Image Back in Imagination." Philosophy and Phenomenological Research 62: 85-109.

Kind, A. 2013. "The Heterogeneity of the Imagination.” Erkenntnis 78 (1): 141-159.

Kind, A. 2016. "Introduction.” In The Routledge Handbook of Philosophy of Imagination, edited by A. Kind, 1-11. New York: Routledge. 
Kind, A. and Kung P., eds. 2016. Knowledge Through Imagination. Oxford: Oxford University Press.

Lamarque, P. and Olsen S. H. 1994. Truth, Fiction, and Literature: A Philosophical Perspective, Oxford: Oxford University Press.

Langland-Hassan, P. 2012. "Pretense, Imagination, and Belief: the Single Attitude Theory." Philosophical Studies 159 (2): 155-179.

Liao, S. and Doggett, T. 2014. “The Imagination Box,” Journal of Philosophy 111 (5): 259275.

Liao, S. and Gendler, T. 2018. "Imagination.” In The Stanford Encyclopedia of Philosophy, edited by E. N. Zalta. URL = <https://plato.stanford.edu/archives/win2018/entries/imagination/>.

Martin, M. G. F. 2002. “The Transparency of Experience.” Mind and Language 4 (4): 376425.

Matravers, D. 2014. Fiction and Narrative. Oxford: Oxford University Press.

Nichols, S. 2004. "Imagining and Believing: The Promise of a Single Code." Journal of Aesthetics and Art Criticism 62 (2): 129-139.

Nichols, S. 2006. "Just the Imagination: Why Imagining Doesn't Behave Like Believing." Mind and Language 21 (4): 459-474.

Nichols, S. and Stich, S. 2003. Mindreading: an Integrated Account of Pretence, SelfAwareness, and Understanding of Other Minds. Oxford: Oxford University Press.

Peacocke, C. 1985. "Imagination, Experience, and Possibility: A Berkeleian View Defended.” In Essays on Berkeley, edited by J. Foster and H. Robinson, 19-35. Oxford: Clarendon.

Radford, C. 1975. “How Can We Be Moved by the Fate of Anna Karenina?” Proceedings of the Aristotelian Society, Supp. Vol. 49: 67-80. 
Schellenberg, S. 2013. "Belief and Desire in Imagination and Immersion." Journal of Philosophy 110 (9): 497-517.

Stock, K. 2011. "Fictive Utterance and Imagining." Proceedings of the Aristotelian Society, Supp. Vol. 85 (1): 145-161.

Stock, K. 2013. “Imagining and Fiction: Some Issues.” Philosophy Compass 8 (10): 887-896.

Stock, K. 2016. “Imagination and Fiction." In The Routledge Handbook of Philosophy of Imagination, edited by A. Kind, 204-214. New York: Routledge.

Van Leeuwen, N. 2011. "Imagination is Where the Action Is." Journal of Philosophy 108 (2): $55-77$.

Walton, K. L. 1990. Mimesis as Make-Believe. Cambridge MA: Harvard University Press.

Walton, K. L. 2008. Marvelous Images. New York: Oxford University Press.

Walton, K. L. 2015. In Other Shoes: Music, Metaphor, Empathy, Existence. New York: Oxford University Press.

\section{Notes}

${ }^{1}$ This is the main claim made by the "standard" (Friend 2012, 182) or "consensus"

(Matravers 2014, 21ff) view of fiction. See, e.g., Currie (1990, 1991); Davies (2007); GarcíaCarpintero (2019; forthcoming); Lamarque and Olsen (1994); Stock (2011; 2013; 2016); Walton $(1990 ; 2008 ; 2015)$. It is also tacitly assumed in discussions about imagination in general; see the works cited in the next note. Friend $(2008 ; 2011 ; 2012)$ adduces several counterexamples, but accepts that prescribing imagining is a standard property of fiction (2012, 188). Matravers (2014) suggests abandoning the distinction between fiction and nonfiction in favor of the distinction between what he calls "representations" and "confrontations." 
${ }^{2}$ See, e.g., Doggett and Egan (2007; 2012); Gendler (2003); Ichino (2019); Kind (2013;

2016); Langland-Hassan (2012); Liao and Doggett (2014); Liao and Gendler (2018); Nichols and Stich (2003); Nichols (2004; 2006); Ravenscroft and Currie (2002); Schellenberg (2013); Van Leeuwen (2011); Walton $(1990 ; 2008 ; 2015)$. Another claim is that imagining also has sensory components; see, e.g., Kind (2001), Peacocke (1985); cf. Schellenberg (2013, 499). My argument is compatible with this claim, but focuses on belief-like, propositional, imaginings.

${ }^{3}$ Walton's invocation of 'function' ensues from the fact that his analysis of fiction does not require authorial intention, or any intention of the sort associated with speech acts (1990, 86ff). This paper does not discuss whether fictionality necessitates some kind of intention on the part of the author. My focus is the audience response that a work of fiction mandates, namely, the mental activity that is associated with imaginings; my argument is therefore compatible with both sides of the 'intention' debate.

${ }^{4}$ My account is neutral as to whether or not beliefs are normative or 'aim at truth.' The point is that beliefs and imaginings are alike in that their content is putatively assessed for truth in a world, hence they themselves do not determine the relevant truths.

${ }^{5}$ In engaging with fiction, we may, obviously, misinterpret what the work mandates us to imagine, and posit an i-truth that it hasn't directed us to posit. Indeed, ascertaining what a work mandates us to posit to be i-true (and, likewise, what it mandates us to imagine) sometimes requires that the work be interpreted in its entirety, rather than passage by passage; see, e.g., Walton (1990, 145-146). Such a (real-world) mistake in interpreting the work's mandate should not be confused with the 'incorrectness' ascribed to imagining of ifalsehoods mandated by the work, as in the murder-mystery case.

${ }^{6}$ García-Carpintero (2019, section 3) distinguishes between "ancillary imaginings" and “constitutive imagining." His distinction seems to overlap the distinction between (belief- 
like) imaginings and positing, although his motivation is different from mine, and applies only to engagements with fiction. See also García-Carpintero (forthcoming).

${ }^{7}$ Philosophers generally maintain that imagining an overt contradiction is impossible (see Kind 2013, 151). A solution to the third problem that accepts that contradictions cannot be imagined is therefore preferable to a solution based on imagining a contradiction. Walton himself argues that imagining two conflicting propositions is possible only if each proposition belongs to a different cluster (2015, 30-31).

${ }^{8}$ An anonymous referee pointed out that all fictions, in a sense, are of the real world. For every work of fiction seems to (implicitly) ask us to imagine, regarding the real world, that this and that happened. The point is well taken: works of fiction are, to a great extent, about real-world objects and properties. When Fred, e.g., imagines that he is rich, he imagines of his real-world self, and of the real-world property of being wealthy, that the former has the latter. This claim, however, must be distinguished from my claim that imaginings are 'directed at' an i- world. My claim has to do with assessment for truth: imaginings are directed at an i- world in that their content is putatively assessed for truth in an i- world. Were our imaginings directed at the real world, their content would be putatively assessed for truth simpliciter, which is patently false. For were this the case, our imaginings would be responsive to real-world evidence, consistent with our beliefs, etc., and hence would not be imaginings. Though imaginings often refer to real-world objects and properties, we take their content to be putatively assessed for truth in an i-world; with respect to the truth of imaginative content, what matters isn't the real world, but the posited i-world.

${ }^{9}$ On the acquisition of new beliefs — and on some views, even new knowledge — through imagination, see, e.g., Davies (2007, ch. 8); Kind and Kung (2016); the issue exceeds the scope of this paper. 